\title{
The standard of axes in ontology of communication
}

\author{
Jozef Novak-Marcincin ${ }^{1}$, Daniela Gîfu ${ }^{2, *}$, Adrian Nicolescu ${ }^{3}$ \\ ${ }^{1}$ Technical University of Kosice, Slovakia \\ 2“Alexandru Ioan Cuza” University of Iaşi, Bd. Carol I no. 11, 700506, Romania \\ 3 University of Craiova, 13 A. I. Cuza Street, 200585, Craiova, Romania \\ *E-mail address: danigifu@yahoo.com
}

\begin{abstract}
An ontology together with a set of individual instances of classes constitutes a knowledge base. In reality, there is a fine line where the ontology ends and the knowledge base begins. For the purposes of this study an ontology is a formal explicit description of concepts in a domain of discourse (classes, Sometimes called concepts), properties of each concept describing various features and attributes of the concept (slots, sometimes called roles or properties)), and restrictions on slots (facets, sometimes called role restrictions) (Gruber, 1993; Vlăduțescu, 2013).
\end{abstract}

Keywords: communication; ontology; ontology of communication; axes of communication

\section{INTRODUCTION}

In 2005, at the Annual Conference of the International Communication Association (ICA), New York, May 28, 2005, Wolfgang Donsbach noted the following about "the identity of communication research: Thesis 1: Communication as a research field has seen the greatest growth of probably all academic fields over the last 30 years" (Donsbach, 2006, p. 437, Vladutescu, 2014). In Thesis 2, the study on the "identity of communication", Wolfgang Donsbach mentions, that "field increasingly suffers from epistemological erosion" (Donsbach, 2006 , p. 446). Therefore, these are some of the ideational nuclei where the "field as a field" deterioration and its metamorphosis in the "universe" were found (Vladutescu, 2014). Robert T. Craig established an ontological standard revealing the ideational outlooks that cross and make the communication field accessible. Therefore, the grid includes the initial seven traditions: rhetorical (views communication as the practical art of discourse), semiotic (views communication as the mediation by signs), phenomenological (communication is the experience of dialogue with others), cybernetic (communication is the flow of information), socio-psychological (communication is the interaction of individuals), socio-cultural (communication is the production and reproduction of the social order), critical (communication is the process in which all assumptions can be challenged) and four potential traditions: "feminist tradition", "aesthetic tradition", "economic tradition", "spiritual tradition" (Craig, 1999, p. 151).

The communication world changed definitely and around the year 2000, there was a mild paradigm change and a new "Communication-as-a-Multi-field (Multi-space)-and-Multistructure-Universe” epistemic object took shape (Vladutescu, 2013). Since ontology remained 
fixed within communication-as-a-field frames, it has been currently experiencing a "relaxed" shortage of communication ontology. Thus, the problem is that the communication-as-anuniverse reality cannot be conceived within the communication-as-a-field lexicon. In the attempt to build a new ontology on the foundations of the old ontology, it has been found that communication-as-a-field actually had a stronger implicit ontology than the explicit ontology founded by S. Deetz, G. J. Shepherd, C.R. Berger, R. T. Craig, J. K. Burgoon, S. W. Littlejohn, shows professor Vladutescu. At a more in depth examination, we will understand that communication-as-a-field worked without a clear and dedicated ontology (Vlăduţescu, 2004). The specialists in communication identify the "claim components" within theories/sciences

\section{AXES OF AN ONTOLOGY}

Professor Vladutescu, in his researches, asserts: "Our remark is that these organizational lines are not external vectors, but internal vectors. Thus, we refer to these as organizational vectors axes. Our thesis shows that the Communication-as-an-Universe can be organized along 15 axes, and hence we refer to the organization grid as the Communication Axes MatrixStandard. Furthermore, we differentiated four hard axes which are defining for the communication domain: communication ontology-A1, communication epistemology-A2, communication methodology-A3, and communication axiology-A4. At the same time, we retained the other 11 axes as qualifying, differentiating axes and soft axes: communication history-A5, communication psychology-A6, communication sociology-A7, communication anthropology-A8, communication hermeneutics-A9, communication praxeology-A10, communication ethics-A11, communication logics-A12, communication ecology-A13, communication philosophy-A14, and communication law-A15".

Also, Professor Vladutescu argues in the favor of the thesis that communication as an academic discipline is facing many uncertainties. One of these is the uncertainty regarding the status. Nuclear question about the status of the communication: the study of communication is a theory or a science, is a weak cogitative system or a strong cogitative system? "We distinguish five causes that determined communication study to remain to this day a weak cogitative system: the effervescence of the theoretical-scientific and practical researches in a knowledge area full of promises; heavy coagulation of a cogitational communication community; refusal of the rule; articulation of communicational thinking as "weak thinking" -"weak thought" (G. Vattimo); and the delay in the development of the communication ontology". Discipline that studies communication is a weak-cogitative thinking system, a sum of theories but not yet a science. As a set of weak theories, the study of communication is becoming science In any case, discipline that studies communication is on the way to become a science. A theory of communication can be based on interpretation, but a science must be objective, methodical, systematically and should allow for verification (Vladutescu, 2014). L. Duarte and B. Alonso also speak about this; they see the future of communication sciences as "based on objectivity, truth, and empirical verification as the only method of approaching reality" (Duarte L., Alonso G., 2008).

There is no ontology perfect. All indexes of categories and concepts have questionable parts, and some ontological models are contradictory. All ontologies are imperfect. Most of them have specific problems that are solved by applicative or technical-scientific research. The weak ontology of communication has however structuring difficulties: the patterns are common and divergent, the theories are many and unclear, some concepts are not thoroughly grounded, 
the network of categories is not articulated in a coherent whole within one science. Out of these, theories are the weakest and most toxic part. The multitude of theories is what undermines the consolidation of a unitary understanding of the communication process, of the basic ontological elements. A paradox of the communication discipline (of the "communication science", of the "communication theory", of the "communication studies", of the "communicology") is that there was no-one to give legitimization to some theories that could have been legitimated. In other words, the institutionalization was not produced, not because the theories of communication would not have been valuable and appeared as not having "credible legitimacy", but because there was no one to give them legitimacy. And, more specifically, in writing theories, specialists had no more time to give legitimacy to others' theories asserts professor Vladutescu.

Strangely, the history of the communication idea shows that communication specialists do not communicate well towards communication. They do not communicate well with each other. From a cluster of creditable theories, but without many specialists to credit them, strong theory/ science/ communication studies or a communicology could not be created and cannot be created too soon.

In this context, professor Vladutescu Stefan, from University of Craiova-Romania, argues the uncertainties regarding the elements of Communication Ontology from the theoretical universe of communication discipline. There are three primary analytical findings: "a coherent and rigorous ontology of human communication is missing; communication as discipline has no thoroughly explicit ontology; the current rudimentary ontology of communication is under the standards of a rigorous and robust ontology".

Also are identified by professor Vladutescu, the main sources of uncertainty as follows: "the fact that the attitude and behavior of the communication discipline to take seriously as a discipline was established only in 1990's; the fact that a discipline without a secular past, communication cultivates itself as always being at the beginning; the fact that, being always met and treated with courtesy, communication discipline has built hardly "face "among other subjects, leaving a false impression of instability; enjoying success without making waste of effort and acting as "being on her own", communication did not, like other disciplines, the effort to define clear, to establish and impose an ontology" (Vladutescu, 2014).

The general ontology is a picture of existences. The ontology is defined as the study of the categories forming a field of existence likely to be conceptually structured as object of understanding and knowledge. The general ontology deals with the "existence of the object" or with the categories that form the object. In the theoretically modeled ontological practice, a few ontological theorems have been emphasized. The theorems are constructions-inferences made up of multi-axiomatic explanations. A theorem results from the targeted combination of several axioms: "Axioms can be combined to derive theorems" (Gudykunst W., 2005, p. 427). To complete the overview of communication ontology, professor Vladutescu suggests 4 ontological communicational theorems: "the theorem on the distinction between independent entities and dependent entities; the theorem on the ongoing distinction of the communicating agents or participants; the theorem on the distinction between continuants and occurrence; the theorem on the distinction between universals (also called kinds, species, or types) and particulars (individuals, instances, or tokens)".

On the synchronous slope, the ontology means to put into incidence the diachronous vocabulary of the moment in relation to the object, the issue of the field. The object of study of the theory or science is split into categories. The perimeter to investigate is segmented into category plots (Vladutescu, 2014). Therefore, the ontology applied will proceed to either "(1) a scanning of the problem of the targeted field by relating it to shared-validated concepts, or (2) 
the operationally clear and distinct definition of the concepts, with the goal to end in being shared-validated" (Vladutescu, 2014).

Whatever the domain of the discourse may be, it will always mobilize an implicit ontology. All discourses are impregnated by an implicit ontology which is diffused into the structuring and functioning of the discourse. It can be identified. The implicit ontology is a practice, an application of a type of discursiveness; it is the achievement of a directly unveiled project. If the ontological project is presented directly, then we are dealing with an explicit ontology. If the appurtenance of the discourse to an universe of discourse is specified, if the concepts and reference categories are specified, if the theories, paradigms, models and principles used are made known, then we are dealing with an explicit ontology. Explicit ontology is a program of thinking within a ontology. Sometimes the explicit ontology and implicit ontology may not correspond. There is an implicit ontology in any discourse. It is specific to the discourse appurtenance domain. In a philosophical study, we shall necessarily find a philosophical ontology.

When a text in the domain of the communication discipline is subject to the ontological assessment of a typical standard lecturer, the latter will have ontological assignment problems. There are two causes: a) as a discipline, communication does not have a properly set and easily identifiable ontology, and b) the communication culture is still insufficient in order to remedy the ontological ambiguity of communication through it.

The ontology, as perimeter of the lexicon, of the concepts, categories, taxonomies, paradigms, models and principles, dictates the specific nuances. The implicit ontology has the conceptual-category vocabulary and taxonomies, classifications as first criterion of determination. Essentially, it is a matter of two "lists".

The ontology is the royal way. It is axis 1 of any discipline. The ontology of the human communication is axis 1, A1, of the discipline of communication, a General Communication Science. It establishes the extension and the elements of the object of any science, including those of the General Communication Science (Vlăduțescu, 2013).

All the other function within this boundary, and when they want to extend it, this could be accomplished only through the ontology. The sequencer axes thesis has two corollaries: (1) ontology, epistemology, methodology and axiology, together with history, psychology, sociology, anthropology, hermeneutics, praxeology, ethics, logics, ecology, philosophy of communication, and communication law represent axes of the cogitation system called General Communication Science; (2) the axes are internal articulations and, as a strong science, i.e. rigorous and robust, General Communication Science describes the whole set of axes as components.

"The fundamental stake of the communication ontology, asserts professor Vladutescu, is to fix a standard lexicon of the theoretical-scientific communication universe. This taxonomic lexicon refers to: paradigms, models, basic cogitations (laws, principles, axioms, postulates, theorems, paradoxes, etc.), essential ontological components (processes, structures, elements like sender, receiver, actant, actor, agent, communicator, message, channel, context, etc.), categories, concepts, and theories" (Vladutescu, 2014).

A lexicon is a flexible standard, which assigns the boundaries and organization to a discipline. Ordering the concepts and categories of communication and systematizing the communication domain are ontological, necessary undertakings that can only be achieved in the environment of a strong and convergent community of the communication specialists. The Ontology of Human Communication is the picture of the existence of communication.

Specifically, the current issue of communication is that although it uses ontology, it has not discursively consolidated an ontology. It has implicit and explicit ontology for each of the 
three paradigms up to now, it has implicit and explicit ontology for the schools representing the paradigms. However, communication does not have an interrogative and convergence "communication ontology". It has a few good dictionaries, but it does not have a discursively founded trans-historical interrogative ontology. It means it does not have an ontology to integrate all entities of the communication universe of study.

To emphasize the importance of ontology in communication, Professor Vladutescu (2014) shows: "Our project is the design of an ontology within an ontology engineering. At this moment, ontology is the universe of existences, of entities, of objects of speech. The current ontology of communication is under the standards of a rigorous and robust ontology. An ontology of an universe is based particularly on the general culture of the science and on the communication within the field. In communication, there has been no ontologically directed communication. Communication also lacks a thoroughly structured vocabulary, as well as a culture of communication. We all discuss communication and cultivate the idea of communication. Everyone speaks of their own job, their own activity. Everyone speaks about the communication specific to their professional, family, etc. environment. The rigorous and robust ontology of a settled discipline becomes noticeable by complying with 3 standards: the fact that science is taken seriously as an ontological discipline; the rare invocation of a selfontological definition; the fact that it is ontologically related to the other disciplines, as in partner-disciplines".

\section{CONCLUSIONS}

In his research on communication ontology, professor Vladutescu (2013) suggested the necessity of ontology of communication for: organizing the communication field in terms of category; systematizing the communication field, communicative entities (concepts, categories, paradigms, theories, models, systemic ontological elements, principles, axioms, theorems); deciding a mutual terminological index; creating the existence and convergence platform for the other axes of study, including itself. Of those axes, ontology is the only one that can speak ontologically, i.e. motivated, and existentially about itself.

\section{ACKNOWLEDGMENT}

In order to perform this research the first author received financial support from the Erasmus Mundus Action 2 EMERGE Project (2011 - 2576 / 001 - 001 - EMA2). I am also grateful to the NLP-Group@UAIC-FII for offering me support in using some tools for automatic interpretation of Romanian language.

\section{References}

[1] Donsbach W. (2008) (Ed.), The International Encyclopedia of Communication, 12 volums. Oxford, UK, and Malden, MA: Blackwell Publishing.

[2] Craig R. T., Communication Theory 9(2) (1999) 119-161.

[3] Andrzej Borowski, International Letters of Social and Humanistic Sciences 14 (2014) 7-17.

[4] Ştefan Vlăduţescu, American International Journal of Contemporary Research 3(10) (2013). 
[5] T. R. Gruber (1993). A Translation Approach to Portable ontology Specification. Knowledge Acquisition, 5, 199-220.

[6] C. E. Ciovica, F. Cristian, V.-A. Enăchescu (2011). Communication and conflict-an intercultural approach. Euromentor Journal-Studies about education.

[7] Paula Bajdor, Iwona Grabara, Journal of Studies in Social Sciences 7(2) (2014).

[8] Andrzej Borowski, International Letters of Social and Humanistic Sciences 14 (2014) $33-41$.

[9] Ioan Constantin Dima, Ştefan Vlăduţescu (2012). Persuasion elements used in logistical negotiation: Persuasive logistical negotiation. Saarbrucken: LAP Lambert Academic Publishing.

[10] Florentin Smarandache (1999). A Unifying Field in Logics: Neutrosophic Logic. Philosophy.

[11] I. Stavre (2011). Comunicare audiovizală: aspecte ale europenizării societăţii româneşti. Tritonic.

[12] Marin Drămnescu (2014). Argumentation for social instruction model from the perspective of social innovation. eLearning \& Software for Education.

[13] D. Gîfu, D. Ionescu, M. Teodorescu, International Letters of Social and Humanistic Sciences 26 (2014) 18-28.

[14] Andrezj Borowski, International Letters of Social and Humanistic Sciences 6 (2013) 86-90.

[15] F. Smarandache, Ş. Vlăduţescu (2014). Neutrosophic Emergences and Incidences in Communication and Information. Saarbrucken: LAP Lambert Academic Publishing.

[16] S. M. Radu, International Letters of Social and Humanistic Sciences 16 (2014) 184-193.

[17] Ioan Constantin Dima, Mariana Man (2014). Information and Computer Engineering in neutrosophic managerial decision. Communication Neutrosophic Routes.

[18] Janusz Grabara, Michal Kolcun, Sebastian Kot, International Journal of Education and Research 2(2) (2014).

[19] Andrzej Borowski, International Letters of Social and Humanistic Sciences 4 (2013) 70-74.

[20] Ştefan Vlăduţescu, International Letters of Social and Humanistic Sciences 25 (2014) 16-24.

[21] Florentin Smarandache, Ştefan Vlăduţescu (2014). Communication Neutrosophic Routes. Columbus, OH: Educational Publishing.

[22] Andrzej Borowski, International Letters of Social and Humanistic Sciences 3 (2013) 46-53.

[23] D. Gifu, I. C. Dima, M. Teodorescu, International Letters of Social and Humanistic Sciences 20 (2014) 46-55.

[24] Ștefan Vlăduțescu, International Letters of Social and Humanistic Sciences 24 (2014) 86-94. 
[25] Borowski A., International Letters of Social and Humanistic Sciences 2 (2013) 56-60.

[26] D. Gifu, J. Novak-Marcincin, M. Teodorescu, International Letters of Social and Humanistic Sciences 27 (2014) 22-33.

[27] D. Gîfu, I. C. Dima, International Letters of Social and Humanistic Sciences 23 (2014) 29-38.

[28] Florentin Smarandache, Ștefan Vlăduțescu (2014). Towards a Practical Communication Intervention. Revista de Cercetare si Interventie Sociala.

[29] F. Liu, F. Smarandache (2002). Logic: A Misleading Concept. A Contradiction Study toward Agent's Logic. arXiv preprint math/0211465.

[30] Ştefan Vlăduţescu, European Scientific Journal 9(32) (2013).

[31] Ş. Vlăduţescu, E. M. Ciupercă (2013). Next Flood Level of Communication: Social Networks. Aachen: Shaker Verlag.

[32] Ștefan Vlăduțescu, International Letters of Social and Humanistic Sciences 10 (2014) 100-106.

[33] Andrzej Borowski, International Letters of Social and Humanistic Sciences 14 (2014) $7-17$.

[34] D. Gifu, V. Modrak, M. Teodorescu, International Letters of Social and Humanistic Sciences 24 (2014) 56-65.

[35] Ştefan Vlăduţescu (2013). What Kind of Communication Is Philosophy. Jokull.

[36] Andrezj Borowski, International Letters of Social and Humanistic Sciences 2 (2014) 110-121.

[37] Florentin Smarandache, Ştefan Vlăduţescu (2014). Neutrosophic Emergences and Incidences in Communication and Information. Saarbrucken: LAP Lambert Academic Publishing.

[38] Andrezj Borowski, International Letters of Social and Humanistic Sciences 3 (2013) 69-74.

[39] Agnieszka Ulfik, Stefan Nowak, Polish Journal of Environmental Studies 23(3) (2014).

[40] A. Borowski, International Letters of Social and Humanistic Sciences 11 (2014) 1-168.

[41] Ștefan Vlăduțescu (2013). Principle of the Irrepressible Emergence of the Message. Jokull.

[42] Andrzej Borowski, International Letters of Social and Humanistic Sciences 3 (2013) 46-53.

[43] Borowski A., International Letters of Social and Humanistic Sciences 7 (2013) 113-118.

[44] G. Rajović, J. Bulatović, International Letters of Social and Humanistic Sciences 6 (2013) 24-35.

[45] Max G. Craig, Journal of Studies in Social Sciences 8(1) (2014).

[46] Ștefan Vlăduțescu, International Letters of Social and Humanistic Sciences 10 (2014) 100-106. 
[47] Colhon M. (2013). Automatic Lexical Alignment between Syntactically Weak Related Languages. Application for English and Romanian. In Computational Collective Intelligence. Technologies and Applications (pp. 266-275). Springer Berlin Heidelberg.

[48] Ștefan Vlăduțescu, Journal of Sustainable Development Studies 6(1) (2014).

[49] M. G. Mangra, E. A. Cotoc, A. Traistaru (2013). Sustainable Economic Development Through Environmental Management Systems Implementation. Journal.

[50] F. Smarandache (1991). Only problems, not solutions!. Infinite Study.

[51] Ștefan Vlăduțescu, International Letters of Social and Humanistic Sciences 7 (2014) 8-13.

[52] J. H. Gasderell, International Letters of Social and Humanistic Science 22 (2014) 85-91.

[53] Ștefan Vlăduțescu, International Letters of Social and Humanistic Sciences 15(2) (2014) 164-170.

[54] Ştefan Vlăduţescu, European Scientific Journal 9(32) (2013).

[55] Vasantha Kandasamy, W. V., \& Smarandache, F. (2013). Subset Semirings. Columbus, OH: Educational Publisher Inc.

[56] Oprea-Valentin Buşu, Mirela Teodorescu, Daniela Gîfu, International Letters of Social and Humanistic Sciences 27 (2014) 82-93

[57] Vlăduţescu, Ştefan \& Ciupercă, E. M. (2013). Next Flood Level of Communication: Social Networks. Aachen: Shaker Verlag.

[58] A. Nicolescu (2014). The role of decentralization in the Romanian public administration system: analysis, theory and models. Revista de Ştiinţe Politice. Revue des Sciences Politiques.

[59] Jason L. Powell, International Letters of Social and Humanistic Sciences 16(2) (2014) 132-143.

[60] Jason L. Powell, International Letters of Social and Humanistic Sciences 17(1) (2014) $1-60$.

[61] Andrzej Borowski, International Letters of Social and Humanistic Sciences 27 (2014) 100-110. 